\title{
FESTSCHRIFT
}

\section{Principlism and communitarianism}

\section{Callahan}

J Med Ethics 2003;29:287-291

The decline in the interest in ethical theory is first outlined, as a background to the author's discussion of principlism. The author's own stance, that of a communitarian philosopher, is then described, before the subject of principlism itself is addressed. Two problems stand in the way of the author's embracing principlism: its individualistic bias and its capacity to block substantive ethical inquiry. The more serious problem the author finds to be its blocking function. Discussing the four scenarios the author finds that the utility of principlism is shown in the two scenarios about Jehovah's Witnesses but that when it comes to selling kidneys for transplantation and germline enhancement, principlism is of little help.

Correspondence to: Professor D Callahan, The Hastings Center, 255 Elm Rd, Briarcliff Manor, NY 10510, USA;

callahan@

thehastingscenter.org

Accepted for publication 27 June 2003
A I am sure Raanan Gillon can appreciate, one of the advantages of spending many years in a field is that of watching fashions come and go. Bioethics is still a comparatively new discipline but it already has a history, one marked by change and development. Principlism-as the "four principles" approach is typically called in the US-emerged as a way of dealing with ethical decisions in the 1970s, was dominant in the 1980s, and then saw a decline in the 1990s (at least so it seems to me). That decline can plausibly be traced to a variety of criticisms, to the emergence of other bioethical methods, such as feminist ethics, narrative ethics, and an emphasis upon empirical rather than foundational work. But even as fashions change it is rare that the old is wholly displaced by the new. Raanan Gillon in the UK, and James Childress and Tom Beauchamp in the US, are three important thinkers who have held their ground.

More generally, however, my impression is that there has been a declining interest in ethical theory over the years, not only in principlism but in most other attempts to find some solid and lasting, and yet useful, foundations for moral judgments in medicine. A glance at the history of the theory discussion is illuminating.

Here is my version of that history. The first thrust, appearing also in the early 1970s, had two tracks. One of them was a debate about whether medical ethics had, and should have, its roots in the history and traditions of medicine, its own and unique ethics, so to speak-and many people in medicine were drawn to this approach; or whether medical ethics should simply draw upon more general ethical theories and principles, of a kind applicable to every other human activity.

When philosophers began being drawn to bioethics they quickly voted for the latter ap- proach, and in particular initially brought to bear the old but still lively arguments about utilitarianism and deontology, hoping that one of those theories, or some combination of both, would provide the needed ethical foundations for the field. But those theories turned out to be too broad and cumbersome to be useful for clinical decision making or policy formation. Principlism, as a middle level approach, seemed much more helpful and more attuned to different kinds of ethical problems. It seemed to have a special appeal to physicians not too interested in ethical theory, but in need of a way of thinking through their ethical dilemmas. That was the attraction of principlism. I base this judgment on years of reading manuscripts submitted to the Hastings Center Report and many articles in the Journal of Medical Ethics. In the US, the Beauchamp and Childress textbook, Principles of Medical Ethics, was by far the most popular medical ethics textbook in the 1980s and 1990s for classroom use (and probably still is). ${ }^{2}$

But what also began catching my eye in recent years was a general decline in the earlier effort to find some defensible foundation for medical ethics, and less and less use of some perspicuous theory to make ethical decisions. I say "perspicuous theory" because it is often possible to detect a tacit theory below the surface even in articles that appeared to rest upon no particular theory at all. Most strikingly, although just about every collection of bioethical articles for class room or general use begins with a survey of ethical theories, most of the collected articles-taken to be the best available-show little evidence of a conscious use of any of those theories.

For my part, at any rate, I never lusted in my heart for some knockdown theories, rules, or principles, as if no decent ethical thinking could do without them. At the same time, even though I have many problems with principlism, as I will shortly explain, I am ambivalent about it; it has its uses and misuses. But before saying more about principlism, and Dr Gillon's four cases, ${ }^{1}$ I will say a little about my own approach to ethics, to provide a context for my criticisms and response to his cases.

\section{COMMUNITARIANISM}

I might be characterised as a communitarian philosopher. I hold that the first set of questions to be raised about any ethical problem should focus on its social meaning, implications, and context, even in those cases which seem to affect individuals only. The dominant model for me is one I draw from ecology. The important question for ecologists is always, with old or new habitats, how any individual plant will live with and affect every other plant. When a new species is 
introduced into a marsh, for instance, the central issue is not how well it will individually flourish, though that is interesting, but what it will do to the network of other species. Will it live in harmony with them, perhaps improving the whole ensemble, or at least do no harm, or will it prove destructive?

Communitarianism, as I construe the term, is meant to characterise a way of thinking about ethical problems, not to provide any formulas or rigid criteria for dealing with them. It assumes that human beings are social animals, not under any circumstances isolated individuals, and whose lives are lived out within deeply penetrating social, political, and cultural institutions and practices. It also assumes that no sharp distinction can be drawn between the public and private sphere. It is important that there be a private and protected sphere, but what counts as private will be a societal decision, not something inherent in the human condition.

\section{ANALYTICAL SKILLS}

The key to a communitarian way of thinking comes down, for me, to a set of analytical skills and personal virtues, not a set of decision procedures. The most important analytical skills are rationality, imagination, and insight. Rationality, as the history of philosophy and ideas demonstrates is no simple concept. Moralistically urging people to be rational, as if that will solve their problems, is simply naive. None of us, for instance, can rationally defend our ultimate premise and starting point; there is always some beginning leap to be made. Reason can not judge reasoning without finally begging the question. Nor should reason be sharply separated from emotion. Our reasons ordinarily embody and express some emotions just as our emotions embody some cognitive judgments. Our untutored emotions are useful signals, repugnance or gut attraction a possibly meaningful flag to catch our moral attention, requiring closer examination.

Rationality is important, but it is never enough. The worst possible mistake on the part of philosophers, all too common, is to think that good ethics comes down to good arguments. It is as if an anatomist thought that human nature could best be understood by stripping all the flesh off a body to uncover the hidden bones. Many good arguments have been adduced in support of wrong moral positions. Rationality at the least needs the help of the imagination. At the clinical level this means, for instance, an ability to enter into the needs, pain, and suffering of others, to grasp their situation and respond appropriately to it. At the policy level it means understanding-for example, how a proposed health care reform might not only improve health or access to health care, but how it could play out in the larger political and social scene. This is, if you will, just a form of consequentialism. The contribution of the imagination is not just to see what logically might follow from a clinical or policy decision, in a chain of cause-effect relationships, but what might, in the hurly burly of real life, actually happen, logically or not.

Insight, or what might be thought of as sensitivity, is necessary to understand the embedded quality of our lives. By that I mean the effort to take the measure of the culture of which we are a part, either the narrow culture of medical practice and institutions, or that of the wider society in which they are set; and of the way they interact with and influence each other. While common sense and a sharp eye may still be the best routes to insight, the social sciences have important contributions to make. They can help us see the finer social texture of, say, a neonatal intensive care unit or that of a health maintenance organisation. The fresh emphasis in recent years on social science information and concepts is as important a sign as any of a move away from the search for an ethical lodestone in some large philosophical theory.

\section{PERSONAL SKILLS}

Closely related to the analytical skills, but not quite the same, are what I think of as personal skills: knowledge of moral traditions, theories, and arguments; self knowledge; and an ability to see in what ways and to what extent one's moral analysis reflects the influence of the class and intellectual culture to which one belongs.

A knowledge of moral traditions, theories, and arguments hardly requires any elaborate defence. Yet it is remarkable, for instance, how many of those trained in philosophy have no knowledge of religious traditions, and often seem hostile to even learning about them. Or how physicians sometimes scorn what philosophy might contribute to their moral thinking, dismissing it as too abstract or too little shaped by clinical experience.

Self knowledge would seem to need little defence also. But I have often been astonished by a kind of psychological naivety on the part of some in ethics who fail to see the way their professional role, or their circle of friends and colleagues, appears to shape their moral judgment. They are part of the crowd but seem unable to notice that about themselves, their views as predictable as that of the company they keep. Once we understand that we are not isolated, autonomous individuals making up our own minds apart from others, a key part of a communitarian outlook, we do not become inoculated against that kind of blindness but are in a better position to be alert to it.

\section{PRINCIPLISM}

I have taken a long time to get to the main subject, that of principlism. But I have tried to lay out my own approach to ethics as a way of saying that a rejection of principlism, which has some powerful attractions, must rest upon something more substantive than a rejection of arguments in its behalf. Taken in its own terms, principlism has two key virtues: it reflects the liberal, individualist culture from which it emerged, and is thus culture congenial; and it is relatively simple in its conceptualisation and application, and thus particularly attractive to clinical decision making. It is the first virtue that concerns me much more than the second. One ought not to have to be a philosopher to deal with the moral problems of clinical medicine or, for that matter, of health policy. It is helpful to have some reasonably clean ways to cut through the experiential and social dimensions of actual decision making, where time and knowledge are limited. On that score, principlism achieves one of its purposes, which has been that of finding a middle range of useful, relatively clear principles.

For me, however, two problems have stood in the way of any enthusiastic embrace: its individualistic bias, and its capacity to block substantive ethical inquiry.

The individualism underlying principlism is best seen in the central place given to autonomy. While it is putatively only one of four principles, in the uses of principlism I have noticed over the years the other principles seem ineluctably to lead back to it. Non-maleficence, for instance, comes down to a right not to have our mind or body harmed by another, to be left intact; and that is a historical variant of autonomy.

Beneficence has always had an unclear place, in great part because to act kindly or generously toward others requires that we have some sense about what is actually good for them. But of course liberal individualism is nervous about going in any direction labelled "the" good of another, as if that was something that others, not the individual himself, could determine. It is no accident, I suspect, that only religious believers are willing to take beneficence seriously, and usually because they are part of traditions that make that both possible and desirable. As for justice, I take it that the whole point of treating people justly, or allocating resources to them in an equitable manner, is to allow them to function as autonomous persons, not discriminated against or harmed by inequitable treatment. 
Autonomy is, then, in fact given a place of honour because the thrust of individualism, whether from the egalitarian left or the market-oriented right, is to give people maximum liberty in devising their own lives and values. A longstanding complaint against principlism is that it has never embraced some system of lexical ordering and is thus in a poor position to deal with conflict among the principles. As a formal point that is no doubt correct. But if I am right in my reading of the typical deployment of principlism, the only important conflicts are between autonomy and the other principles, and all such conflicts are meant to be resolved in a way that does minimum damage to a person's autonomy-since it is that autonomy to which the other principles point back. Principlism is thus not nearly as rich a moral theory as initially seems the case; in fact, it is a kind of one note theory with a few underlying supportive melodies.

Yet there is a more serious problem with principlism, what I think of as its blocking function. Instead of inviting us to think as richly and imaginatively about ethics as possible, in fact it is a kind of ethical reductionism, in effect allowing us to escape from the complexity of life, and to cut through the ambiguities and uncertainties that mark most serious ethical problems. That can be helpful, but often it is not. By focusing on what might be termed the external conditions of moral decision making, its sociolegal context so to speak-our right to make our own choices and to be treated fairly and kindly-it unwittingly invites us to stop our moral analysis at that point.

Yet a probing moral analysis requires a substantive joining of the external and the internal. Autonomy as a moral principle ought to encompass not simply our right to make our own choices whenever possible, but also lead us to take seriously the ethical implications of the different choices open to us, whether in our public or private lives. Serious ethics, the kind that causes trouble to comfortable lives, wants to know what counts as a good choice and what counts as a bad choice. One of the most pervasive moral mistakes is to think that, if a choice is labelled as private, then moral standards no longer apply. But historically ethics has always given a high place to the way we shape and live our lives and the values we embrace. That is a tradition not to be neutered in the name of privacy and some black box called the personal.

Non-maleficence should encompass not simply physical harm or interference with liberty, but threats posed to people's values, social relationships, and political welfare. It is a principle that should lead us to consider what truly harms human welfare, whether from environmental, cultural, or political threats. Beneficence should include an effort to determine just what constitutes the good of individuals even if that means trespassing into the territory of comprehensive theories of the human good. Any such effort requires community reflection and support. Justice as a principle requires not only a judgment about what constitutes a fair distribution of health care resources but must, in the face of scarce resources, also determine just what constitutes appropriate resources to distribute or which should be created by research advances. Some substantive notion of the human good is needed to give justice real bite.

\section{THE FOUR SCENARIOS}

With these long prefatory remarks behind me, I turn now to the four scenarios. ${ }^{1}$

\section{The "standard" Jehovah's Witness case}

This "standard" case is perfectly fit to serve as a kind of poster child for the principle of autonomy. It is of course helpful that the patient is able to receive an alternative treatment to a blood transfusion by means of non-blood products. And it is no less helpful that the costs of such an alternative are not terribly high and that, in any case, the number of those wanting that alternative for reasons of religious belief is few. In short, there is nothing at all lost by recognising the patient's autonomy, either morally or economically.

A more difficult, but also "standard," case would be one in which a blood transfusion was the only feasible treatment to save the patient's life and where, to complicate matters, the patient's family might suffer grievously because of his death. But even in those cases, most Western societies would grant the patient's right to make the life or death choice. In line with my argument above, however, we might well feel free to remonstrate with the patient, arguing that his is a wrong moral choice based on mistaken religious beliefs. If we accept the notion that self regarding choices are open to outside moral judgment and critique, though not to legal coercion, we cannot do otherwise. And if it appears that others would be affected by the decision, it ceases to be one that can fairly be characterised as private only; it has taken on an important community dimension.

\section{The "standard" child of a Jehovah's Witness case}

This case also seems open to an application of principlism. In this instance it is the pertinence of non-maleficence with respect to the welfare of the child that comes into play. And perhaps the principle of justice as well is applicable: it would not be fair to a child to have its life threatened in ways that benefits only the parent. American courts, together with those in the UK, I gather, have consistently refused to allow Jehovah's Witnesses to refuse blood transfusions for their children as a way of following their religious beliefs.

Yet this is an extreme case of parental desires and beliefs. We might well want to ask whether principlism could help us cope well with other kinds of parental desires, and particularly those based on supposedly "rational" grounds rather than unusual religious beliefs. What about a parental desire to clone a child genetically identical to an earlier child who died? Or to select various traits-height, eye colour, for instancedesigned to give parents a child who pleased various fancies of theirs? Since many parents already carry out various "natural" procedures with their children-indoctrinating them with certain values, forcing the discipline of an education on them, aspiring that they follow the parents into law or medicine or philosophy, and sometimes cajoling them to do so-why should we balk at using genetic techniques to achieve the same or comparable ends?

I would invoke two principles in response to such a question. Beneficence would be relevant, forcing us to ask just what kind of formation, genetic or otherwise, is truly good for children. That line of thought should lead us to contemplate the entire life span of a child, asking what the early formation will mean in the long run. Now while it might be difficult, and not entirely desirable, to separate parental hopes and desires from the long term welfare of their children, the possibility of genetic enhancements should underscore the importance of making such an effort. All of us can think of children and adults whose lives have been distorted by overly ambitious or interventionist parents; and all of us can think of children who have benefited from parents whose goals and ideals for their children were kindly and thoughtful.

If, then, beneficence does not tell us just what we should want for our children, or where to draw the line at possible genetic enhancements, the principle of non-maleficence can supply at least two important boundaries. One of them is to remind parents that they can as parents do their children harm, even when the harm is done in the name of some supposed good; care and caution are imperative. The other contribution is that a robust understanding of non-maleficence should forcefully tell us that we should do nothing in the name of enhancement that a child could not reverse as it moved into adulthood. While it is of course possible that a 
parent's psychological manipulation and coercion of a child might require a long psychoanalytical regimen to reverse, for the most part children can get over or otherwise escape their parents' influence. Any supposed enhancement that would, in principle, be irreversible would be an unacceptable intervention into a person's future and individuality, a direct threat to someone's autonomy.

\section{Selling kidneys for transplantation}

If with the other two cases I have not had much trouble showing the utility of principlism, this case begins to show some of its profound limitations. The most important is that it forces us to look for a way of analysing it that goes beyond principlism-forcing us, I would contend, into a communitarian perspective.

The puzzle at the heart of this limitation is that, by most understandings of the four principles, the selling of kidneys should easily pass muster. Unless we think it in principle irrational for someone to want to sell a kidney, which no one claims, then the principle of autonomy would be respected by permitting competent individuals to do so. There is some potential harm, two kidneys being better than one, but a relatively slight harm, well within the bounds of other socially permissible risks. To be sure, there is the possibility of contextual coercion, for instance that of poverty, leading someone to do something for money that the more affluent would not do. That could be seen as a violation of the principle of justice.

Yet it would seem grossly paternalistic to deny someone the right to sell a kidney simply because someone with more money would not do it. We do not refuse people the right to work in mines or at other hazardous occupations just because those of us better off shun such work; and the rest of us depend upon some people being willing to do it. The fact that someone will die if they do not get the needed kidney, which but for its purchase would not be available, would seem the clincher: the autonomy of the donor is respected and the act reasonably compensated for the hazards, and someone's life is saved.

Yet despite the relative ease of making a moral case for the selling of organs (particularly if enhanced by careful oversight and decent financial compensation), most developed countries have strongly resisted moving in that direction. Only in the past few years has a minority voice emerged saying that maybe it wouldn't be so bad after all-a voice that seems swayed by the rhetoric of the market. It is sometimes not sufficiently noticed that what liberals think of as their great principle, that of autonomy, gets no less enthusiastic support from the market oriented right: competent people in democratic societies should have a right to buy and sell what they like.

But that position is still, thankfully, a minority voice. Why the resistance among the majority, including legislators, who have made it illegal in most countries? My guess is not because it would be a practice inconsistent with cherished liberal principles. As I indicated above, those principles would appear to support it. Raanan Gillon, however, has concluded that there would be an excess of harm over good and that, therefore, banning the sale of kidneys can be justified. Since principlism allows no method of balancing harms and benefits, and indeed since no calculus exists for doing so in this case, I am compelled to look for some underlying determinant. What is the source of the uneasiness leading most people to tip toward a ban? Principlism by itself does not offer a sufficient motive, and could just as well point in the other direction.

I can only offer a hypothesis in answer to my question. It is that, at some deep level, the idea of selling vital organs, even to save life, seems, first, a threat to the integrity of our bodies; and, second a threat to the notion of a decent society. On the first point, an analogue may be suggested. In On Liberty John Stuart Mill argued that it would be wrong for someone to sell himself into slavery. ${ }^{3}$ He offered no full argument for that position, no doubt thinking it required none. But there is nothing else in that essay to provide a basis for such a rejection; and, it might be said, his general position could not provide such a rejection. Yet reject it he did, and no one has complained that he was inconsistent and that he should have accepted self chosen slavery. My surmise is that, as an opponent of slavery, he believed that it was such an offence to human dignity and freedom in and of itself, that even self chosen slavery would be no less an offence. To sell ourselves, or even a part of ourselves, cuts deeply into some important if usually inchoate perceptions of our self worth and the bodily integrity that is one of the markers of that worth.

On the second point, my surmise is that we find the idea of a society where people may want, even freely, to sell their body parts to make ends meet-or even to have some extra money to do with as they please-is not the kind of society in which most of us would want to live. Part of the repugnance may be the belief that it could too easily lead to exploitation; in part to the idea that our bodies are too important for our identity and sense of wellbeing and too intimate to be turned into market items; and in part because we believe that-though we have yet to find it - there must be a better way to procure needed organs (we have no objection to altruistic donations). Some things should just not be put on sale, even if doing so might save life.

In sum, so my hypothesis goes, we are seeing displayed a communitarian response. Using my ecological imagery, this much can be said: while the plant that is the sale of organs might do well itself and benefit recipients, it is a plant that will disturb so many other important values in our moral system, that even if we can offer no decisive evidence of the danger, we think it best to bend over backwards to avoid moving in that direction.

We do not want to legitimate turning our bodies into a collection of marketable products. We do not want to establish a precedent for the saving of life that requires others to put their lives at risk (even if we are possibly prepared to allow altruistic donations). We do not want to live in a society which, in effect, says that nothing is more important than the preservation of life and the relief of suffering, great as those goods are.

We do not want to see autonomy established as a principle that can always trump other considerations. A good, but not sufficiently powerful, reason for banning the sale of organs is the risk of exploitation of poor donors. A more serious reason is that it would put in place a poisonous plant, affecting the way we live our lives and exist together as people and not just what happens to our personal organs.

\section{Genetic manipulation and germline enhancement}

A few years ago I was part of a debate at the Centres for Disease Control and Prevention in Atlanta about the wisdom of destroying the last smallpox virus, thought to be secured and sheltered in a few laboratories in the US and Russia. The argument in favour of destruction was that the possibility of this lethal scourge would once and for all disappear from the human scene. The argument against was twofold: that the virus should be kept for scientific research purposes, and because it might turn out that it actually existed elsewhere, in the hands of evil persons, and it could become be necessary to develop a new line of defence against it. The latter view won, and given the recent upsurge in terrorism, that was thought a wise decision.

I was reminded of this debate by the germline case because of much discussion in recent decades about how we might best understand genetic disease, on the one hand, and dangerous infectious disease, on the other. In the former instance the voice of caution said that most genetic diseases have in some contexts a protective benefit. Sickle cell anaemia, conferring immunity to malaria in Africa, was a favourite 
example. The point was not that we should not attempt to eliminate the disease in African Americans but that nature is not as dumb and lethal as it looks; just be careful, the message was, lest inadvertent harm be done in the war against genetic disease. No such message, so far as I know, has been forthcoming about infectious disease.

The prospect of an effective germline intervention against HIV/AIDS is thus an alluring even if futuristic prospect. The longstanding worry about germline interventions is that they might be irreversible and that they would saddle future generations with genetic changes they had no choice about. Is this a plant we want to put into our social ecology? We may get rid of AIDS, but what else will we get? Can we be sure that future generations will thank us, particularly if it should turn out that future scientists discover some important biological reasons why AIDS turned out to be, in the long run, a human benefit? Of course we cannot answer such questions, but we are not helpless before them.

I find it helpful with issues of this kind to distinguish between enhancements or medical progress that will benefit population health - a communitarian angle-and those primarily of benefit to individuals. The distinctive feature of infectious disease plagues and pandemics is that they strike at all age groups and can, because of their high mortality rates, kill the young as well as the old, directly harming the infrastructure of societies. AIDS in Africa is killing health care workers, teachers, administrators, and young parents. It strikes directly at the capacity of a society to function as a society. However great the economic and social burden of, say, non-communicable diseases such as cancer and heart disease, no one has ever claimed that they pose a direct threat to the basic institutions of society. AIDS does, as do smallpox, cholera, and the bubonic plague.

The utility of this distinction becomes clearer in trying to determine what might count as a good reason to go forward with germline enhancements. An enhancement designed to benefit individuals, adding some enhanced personality traits that would then be passed along to their descendants, would be worthy of suspicion. Those descendants would have no say in the traits bequeathed to them and, if irreversible, no possibility of freeing themselves from them. That would be irresponsible procreative behaviour, satisfying personal desires at the expense of unborn descendants, and of no special use to the larger community. The possibility of eradicating AIDS would raise no such problem. No future generation would be likely to complain about the results or the motive behind the enhancement. It is conceivable, one must suppose, that some future pathology could be traced to the germline enhancement, but that possibility seems remote and well worth the risk. A disease that kills millions and ruins whole societies has little to be said for it, now or in the future.

I should add, however, that I do not see principlism as offering much help in thinking through the implications of germline enhancement. At a minimum one could invoke maleficence as a reason to not to support germline enhancements that might, conceivably, do harm to future generations. But it would seem to me a stretch to put forth that line of reasoning in support of such enhancement for the eradication of AIDS. That issue points us in the direction of asking just what kind of steps we ought to take for the eradication of disease and the averting of death. Those are basic questions about the appropriate goals of medicine within the appropriate goals of society. At that point, I would argue, we cannot avoid taking a communitarian approach. Or, better put, we can avoid doing so only by asking autonomy to do a kind of work it cannot do, that of telling us what we ought to want as communities, collectively living together, and not just as individuals with different desires and preferences.

To play out this line of thought, let us imagine the use of germline therapy to eradicate, not AIDS (an easy case) but heart disease, the leading lethal non-communicative disease in developing countries. Let us imagine further that the costs of doing so would be enormous, damaging the entire health care budget of a country. If that could be done inexpensively, then there would be no problem (other than the enhanced probability that those who will not die of heart disease will get cancer or Alzheimer's disease-but that is another story). But if expensive, I would contend that the eradication campaign ought not to take place. This is not to deny that heart disease is a misery, blighting the lives of millions. But heart disease does not threaten the very survival of any society, nor does it threaten everyone in a society, much less it younger members. It is increasingly a disease of aging, heavily influenced by (if not easily) modifiable health related living habits. With AIDS on the loose there is no possibility of reaching old age for millions of people.

\section{THE FUTURE OF THE FOUR PRINCIPLES}

As my analysis is meant to suggest, I find the "four principles" approach too narrow to do all the necessary work of ethics, too individualistic to help us answer questions about the appropriate needs of communities, and too mechanical to encourage some necessary analytical and personal skills. Having said that, I cannot help being struck over the years by the way principlism has been deployed, and the great difference it makes just who is making use of it. Unless one is a rigid utilitarian, or even worse an ethical reductionist (only "rational" arguments count), it should not ideally be possible to predict from someone's espoused principles just where they come down on a specific case or problem. One might hope they have been able to overcome their theory, or their crowd, or the zeitgeist of the moment.

If someone has cultivated the analytical and personal skills I have described, they will know that the world and morality are complicated. They will shy away from tidy, mechanical, and deductive reasoning. Nor will they be drawn to other world thought experiments (behind some veil of ignorance), fearful of taking on the world in all of its complexity.

While I have doubts here and there about Raanan Gillon's four principles, I would have no hesitation about becoming his patient. He is too good a doctor and a moral philosopher to fall in love with his own theory, or to let his philosophical predilections stand in the way of his good sense and human sensitivity.

\section{REFERENCES}

1 Gillon R. Four scenarios. J Med Ethics 2003;29:267-8.

2 Beauchamp TL, Childress J. Principles of biomedical ethics [1 st ed]. Oxford, New York: Oxford University Press, 1979.

3 Mill JS. On liberty. In: Collini S, ed. On liberty. Cambridge: Cambridge University Press, 1989 